Journal of

International Logistics and Trade

\title{
Effects of Truck-shared Delivery: A Case of a Korean Mixed Feed Company
}

\author{
Hwa-Joong Kim ${ }^{\mathrm{a}}$, Junwoo Kim ${ }^{\mathrm{b}}$, Woosuk Yang ${ }^{\mathrm{c} *}$, Kyung-Yeon Lee ${ }^{\mathrm{a}}$, Oh-Seong Kwon ${ }^{\mathrm{a}}$ \\ ${ }^{a}$ Graduate School of Logistics, Inha University, Incheon, Korea \\ b Plan Department, Jeilfeed Company, Daejeon, Korea \\ ${ }^{c}$ Jungseok Research Institute, Inha University, Incheon, Korea
}

\begin{tabular}{ll}
\hline ARTICLE INFO & ABSTRACT \\
$\begin{array}{l}\text { Article history: } \\
\text { Received 9 August 2016 }\end{array}$ & $\begin{array}{l}\text { This paper discusses a case of truck sharing as an application of the sharing economy. This } \\
\text { case study examines a real mixed feed company with multiple factories. In this company's } \\
\text { Accepted 17 August 2016 }\end{array}$ \\
$\begin{array}{l}\text { operation, bulk trucks located in a factory had not previously been shared for delivery with } \\
\text { other factories to their pre-assigned customers of stock farms. Therefore, this paper suggests a } \\
\text { ney dering economy }\end{array}$ & $\begin{array}{l}\text { new delivery system that facilitates truck-sharing and analyzes its effects on the transport cost } \\
\text { and trucks' } \mathrm{CO}_{2} \text { emissions. To this end, this paper develops vehicle routing models to } \\
\text { Truck-sharing }\end{array}$ \\
$\begin{array}{l}\text { Vehicle routing } \\
\text { rarbon control policy } \\
\text { models are developed for a carbon control policy of an emission trading scheme (ETS) and } \\
\text { the effects of the ETS on truck-sharing are investigated. Numerical analysis is conducted to } \\
\text { identify the effects of the TSD and the carbon control policy and draw practical implications. }\end{array}$ \\
\hline
\end{tabular}

\section{Introduction}

Owing to the Silicon Valley success stories of Airbnb and Uber, the sharing economy (SE) has recently been receiving a lot of interest from academic researchers, businesses, and policy-makers. PwC (2015) reported a valuation of 15 billion US\$ for SE in 2015, with expected growth to 335 billion US\$ by 2025 . As a result, the SE is affecting various aspects of today's economy including tourism (Queensland Tourism Industry Council 2014; Dredge and Gyimóthy 2015; Forno and Garibaldi 2015), hospitality (Zervas et al. 2016), vehicle (Cannon and Summers 2014), information (Lee et al. 2010), and people's time and skills (Wosskow 2014).

It may be challenging to exactly define the SE (Schor 2014). The common sense meaning of 'sharing' excludes forms of exchange where a monetary benefit accrues to one or more party. According to this definition, well-known SE business services such as Airbnb based on peer-to-peer asset rental could be excluded from the SE (Martin 2016). Thus, all the activities of sharing assets, resources, and even knowledge should be included in the SE in some senses. Based on this broad definition of the SE, this paper discusses a case of truck-sharing within a company, i.e., truck-sharing between factories in the company, each of which is operating trucks.

Since most of the existing studies on the SE have been discussed by Böckmann (2013), Koopman et al. (2015) and Cheng (2016), we confine our review of the previous literature to studies on vehicle-sharing such as car-sharing, bicycle-sharing, and truck-sharing. Car-sharing is a short-period car rental model. In a survey study, Katzev (2003) showed that car-sharing can reduce private vehicle ownership needs, promote greater use of alternative transportation such as bus riding, bicycling, and walking, and induce environmental benefits. Huwer (2004) argued that car-sharing needs to become integrated into public transport and offered operational strategies for successful implementation of a combined service. Bicycle-sharing is a service offering bicycles at multiple locations where users can pick up and drop off at convenient points for next users. Demaio (2009) discussed the history of bicycle-sharing from the early

\footnotetext{
* Corresponding author: Jungseok Research Institute, Inha University, 100 Inha-ro, Nam-gu, Incheon, 22212, Korea

Email:ws.yang@inha.ac.kr
} 
generation program to present day generation programs, and presented the benefits and detriments of each program and a description of capital and operating costs. Nair et al. (2013) have shown that close proximity between bicycle-sharing stations and public transit stops can increase utilization through an empirical analysis of bicycle-sharing systems in France. On the other hand, Lin and Yang (2011) and Lin et al. (2013) considered strategic and operational problems using integer programs like our study. Lin and Yang (2011) considered a network design problem of bicycle-sharing system with the objective of minimizing various operational costs and conducted sensitivity analysis. Lin et al. (2013) extended Lin and Yang (2011)'s model by considering the stock of bicycles and suggested a greedy-type heuristic. Finally, truck-sharing gives individuals access to delivery trucks. Islam et al. (2013) introduced an internet-based truck appointment system allowing the sharing of container trucks in a seaport to improve hinterland transport capacity. They investigated the system using a qualitative approach and showed that the system increased transport capacity, decreased emissions and pollution, decreased transportation rates, and increased driver income. Islam and Olsen (2014) addressed a truck-sharing collaboration among container road carriers pertaining to hinterland transport in a seaport, and performed a survey and interview to find the main obstacles against truck-sharing.

Although Islam et al. (2013) and Islam and Olsen (2014) investigated truck-sharing, they addressed it in a seaport and analyzed truck-sharing systems using qualitative approaches such as a survey and interview. Therefore, we fill the remaining research gap by considering the sharing of bulk trucks for road transport and analyzing it using a quantitative approach based on vehicle routing models. Our paper analyzes the effects of truck-sharing within a Korean mixed feed company on the transport cost and CO2 emissions from bulk trucks delivering feed grains. To do so, our paper develops vehicle routing models to represent the current delivery practice in the case company and a new truck-sharing delivery system. In addition, our paper develops models for a carbon control policy of emission trading scheme (ETS) to investigate the effects of the ETS on truck-sharing.

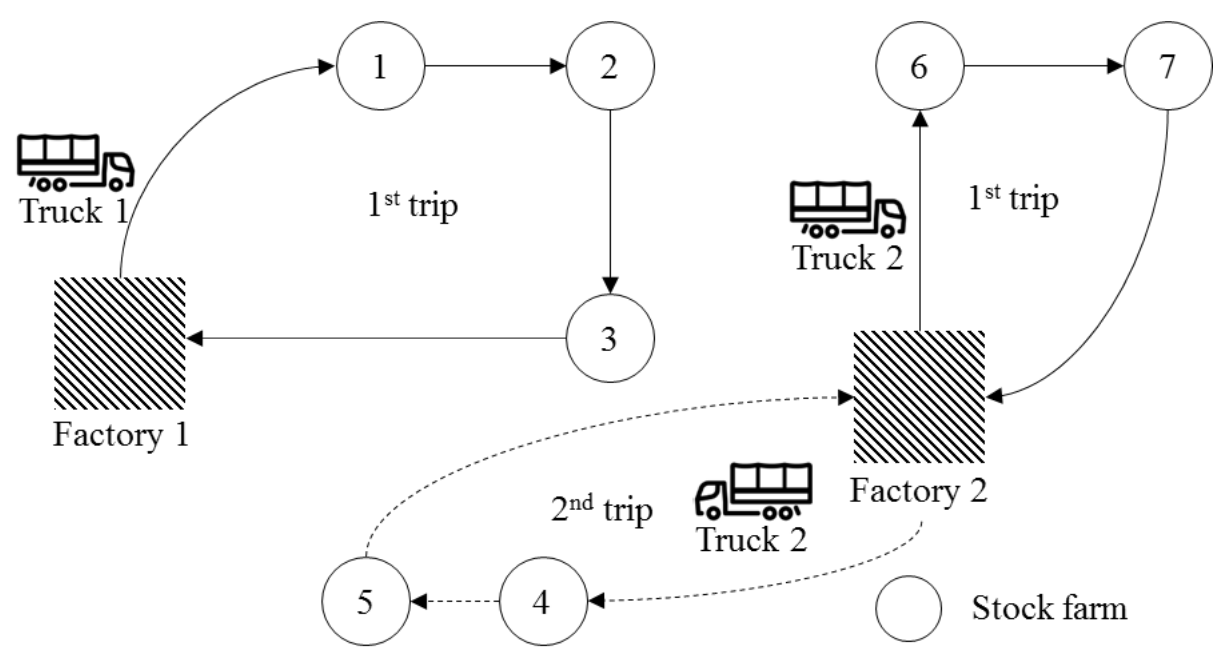

(a) Current non-truck-shared delivery (NTSD)

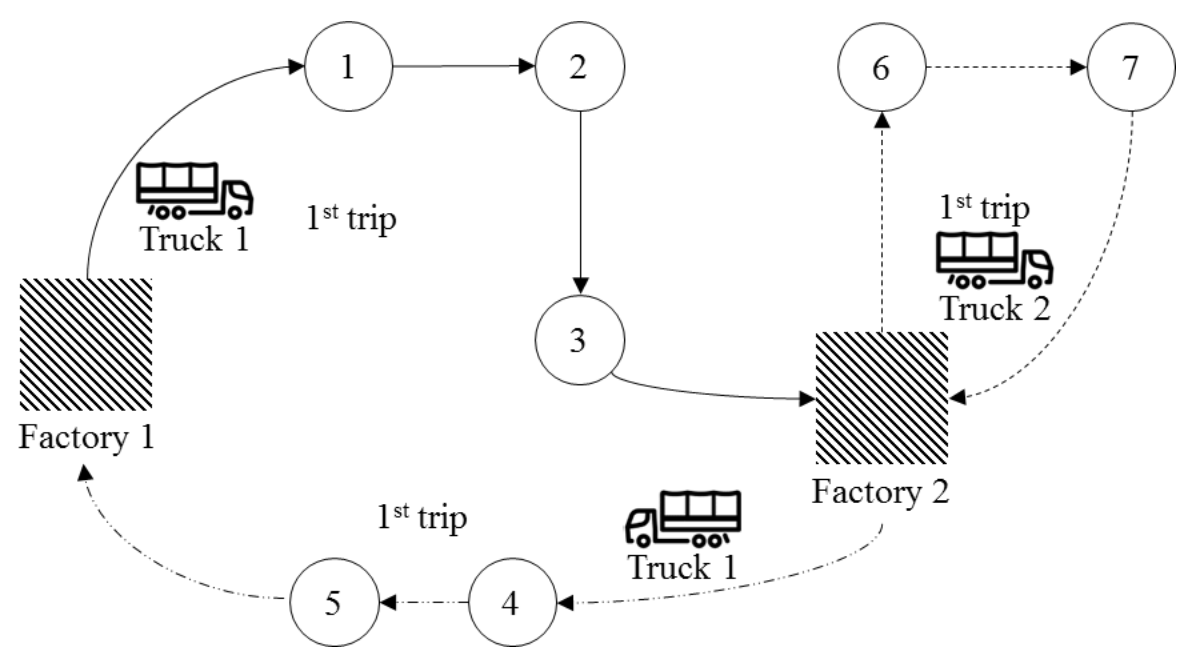

(b) Truck-shared delivery (TSD)

Figure 1. Current non-truck-shared delivery vs. truck-shared delivery 
The paper is organized as follows. The next section describes the current delivery practice in the case company and a new delivery of sharing trucks between factories. Section 3 provides vehicle routing models used for analyzing the effects and Section 4 summarizes the data obtained from the case company and reliable sources. Numerical analysis results and practical implications are summarized in Section 5. The final section concludes by offering future research directions.

\section{Delivery practices in the case company}

The case company produces mixed feed for livestock in its factories and offers an on-demand delivery service to its customers, stock farms. This section describes the current delivery practice in the case company (non-truck-shared delivery: NTSD) and a new delivery system of sharing trucks (truck-shared delivery: TSD).

The company uses special bulk trucks when delivering feed grains from factories or logistics centers to stock farms. For simplicity, the factory or logistics centers are called factory. The bulk truck has three to four storage compartments, each of which separates supplies for different customers as depicted in the truck images in Figure 1. This implies that a truck with three compartments can visit three stock farms at most for example.

At the time of this research, trucks belonging to a factory are used only for the customers pre-assigned to the factory, not for customers to the other factories. This implies that factories do not share trucks each other even in the same company (NTSD), although sharing trucks between factories (TSD) may reduce the delivery cost. The current non-truck-shared and truck-shared deliveries are illustrated in Figure 1 with two factories, two trucks and seven customers as an example. In the current delivery practice in Figure 1(a), customers 1-3 are pre-assigned to factory 1 and customers 4-7 to factory 2 . In the figure, truck 1 belonging to factory 1 travels to farms $1 \rightarrow 2 \rightarrow 3$ in the first trip and truck 2 belonging to factory 2 travels to farms $6 \rightarrow 7$ in the first trip and farms $4 \rightarrow 5$ in the second. As can be seen from Figure 1(a), truck 1 does not visit factory 2 and truck 2 does not visit factory 1 , which implies no sharing of trucks between factories. On the other hand, Figure 1(b) shows example routes when TSD is allowed. Truck 1 belonging to factory 1 travels to farms $1 \rightarrow 2 \rightarrow 3$, and then visits factory 2 to replenish feed grains to serve farms 4 and 5 by traveling to farms $4 \rightarrow 5$ in the first trip, while truck 2 belonging to factory 2 travels to farms $6 \rightarrow 7$ in the first trip. A trip means a journey in which a truck departs from its origin factory, visits some customers or other factories and returns to its origin factory.

\section{Model formulation}

To demonstrate the effectiveness of the new delivery system of sharing trucks between factories in the case company, this paper formulates two vehicle routing models, non-truck-sharing (current) and truck-sharing models, with the objective of minimizing the transport cost. In addition, the models are extended by incorporating the ETS to show the effect of the ETS on truck-sharing. The ETS is a carbon control policy currently adopted by the Korean government in order to regulate $\mathrm{CO}_{2}$ emissions from private sectors.

The models determine the delivery route of multiple trucks departing from and returning to factories after single or multiple trips while satisfying the demand of stock farm customers. The models assume that a truck should start its delivery from a factory to which it belongs and return to the factory after finishing its last trip, that customers should be served by the factory to which they are pre-assigned, that a truck can visit at most as many stock farms as its number of storage compartments, and that a storage compartment is used only for a single customer stock farm.

\subsection{Model for the truck-shared delivery}

The following notations are used throughout the paper:

Sets

I Set of all factories

$J \quad$ Set of all customers

$J_{i} \quad$ Set of all customers served by factory $i$

$K_{j}$ Set of all customers served by the factory serving customer $j$

$T$ Set of all trips

$V$ Set of all trucks

Coefficients

$c_{i j}$ Transport cost from factory or customer $i$ to $j$ 
$d_{j}$ Demand on feed grains of customer $j$

$f_{j} \quad$ Factory serving customer $j$

$i_{v} \quad$ Factory where truck $v$ is initially located

$i_{v}^{+} \quad$ Factory where truck $v$ terminates its trip. Physically, it is the same as the factory $i_{v}$

$m_{v}$ Number of storage compartments available in truck $v$

$q_{v}$ Carrying capacity of truck $v$

Decision variables

$X_{v i j}^{t} \quad=1$ if truck $v$ on trip $t$ travels directly to factory or customer $i$ to $j$ and zero, otherwise

$Y_{v i j}^{t} \quad=1$ if truck $v$ on trip $t$ serves customer $j$ from factory $i$ and zero, otherwise

$Z_{v i j}^{t} \quad$ number of storage compartments used when truck $v$ on trip $t$ travels directly to factory or customer $i$ to $j$

Now, we present the model for TSD, which is a type of multi-depot and multi-trip routing model. This model is thoroughly reviewed in Cattaruzza et al. (2014), Montoya-Torres et al. (2015) and Hernandez et al. (2016). The current NTSD practice can be easily represented using the TSD model because the model for the current delivery practice is a single-depot model and hence the current practice model corresponding to each depot is the same as the TSD model for the depot. In the models below, $I_{v}^{-}=I \backslash\left\{i_{v}\right\}, I_{v}^{+}=I_{v}^{-} \cup\left\{i_{v}^{+}\right\}$.

[TSD-C] Minimize $\sum_{v \in V} \sum_{i \in I} \sum_{j \in J_{i}} \sum_{t \in T} c_{i j} X_{v i j}^{t}+\sum_{v \in V} \sum_{i \in J} \sum_{j \in I_{v}^{+} \cup K_{i}} \sum_{t \in T} c_{i j} X_{v i j}^{t}$ subject to

$$
\begin{array}{ll}
\sum_{v \in V} \sum_{t \in T} X_{v f_{j} j}^{t}+\sum_{v \in V} \sum_{i \in K_{j}} \sum_{t \in T} X_{v i j}^{t}=1 & \forall j \in J \\
X_{v f_{h} h}^{t}+\sum_{i \in K_{h}} X_{v i h}^{t}=\sum_{j \in I_{v}^{+} \cup K_{h}} X_{v h j}^{t} & \forall v \in V, h \in J, t \in T \\
\sum_{j \in J_{i_{v}}} X_{v i h}^{t}=\sum_{j \in J_{h}} X_{v h j}^{t} & \forall v \in V, h \in I_{v}^{-}, t \in T \\
\sum_{j \in J_{i_{v}}} X_{v i_{v} j}^{t}=\sum_{i \in J} X_{v i i_{v}^{+}}^{t} & \forall v \in V, t \in T \\
\sum_{v \in V} \sum_{t \in T} Y_{v f_{j} j}^{t}=1 & \forall j \in J \\
\sum_{j \in J_{i}}\left[\left.\frac{d}{q_{v} / m_{v}}\right|_{Y_{v i j}^{t} \leq m_{v}}\right. & \forall v \in V, i \in I, t \in T \\
\sum_{i \in K_{j} \cup\left\{f_{j}\right\}} X_{v i j}^{t}=Y_{v f_{j} j}^{t} & \forall v \in V, j \in J, t \in T \\
Z_{v f_{h} h}^{t}-\sum_{i \in k_{h}} Z_{v i h}^{t}-\sum_{j \in i_{v}^{+} \cup k_{h}} Z_{v h j}^{t}=\left[\frac{d_{h}}{q_{v} / m_{v}}\right] Y_{v f_{h} h}^{t} & \forall v \in V \\
Z_{v i j}^{t} \leq m_{v} X_{v i j}^{t} & \forall v \in V, h \in J, t \in T \\
Z_{v i j}^{t} \leq 0 & \forall v \in V, i \in I, j \in J_{i}, t \in T \\
X_{v i j}^{t} \in\{0,1\}, Z_{v i j}^{t} \geq 0 & \forall v \in V, i \in J, j \in K_{i}, t \in T \\
Y_{v i j}^{t} \in\{0,1\} & \forall v \in V, i \in J, j \in I_{v}^{+}, t \in T
\end{array}
$$

As described above, the objective function of the model is to minimize total transport cost. Constraint (1) ensures that each customer is visited exactly once. Constraints (2), (3) and (4) represent the travel conservation of a truck such that the truck should leave a customer after visiting the customer and the conservation should be applied also to the factories to which the truck does not belong and the factory to which it does. Constraint (5) implies that each farm should receive a delivery service from the factory with the farm as a customer. Constraint (6) ensures that the number of loaded compartments for a vehicle cannot exceed the number of its compartments. Constraint (7) links two variables 
$X_{v i j}^{t}$ and $Y_{v i j}^{t}$, implies that a truck's visit to a farm in a trip is to serve the farm. Constraint (8) represents the relation of the number of loaded compartments between just before and just after servicing customer $h$. Constraints (9) and (10) imply the restrictions on the maximum number of loaded compartments. Note that constraints (8), (9) and (10) eliminate any subtour in a trip. Finally, constraints (11) and (12) are restrictions on decision variables.

\subsection{Model for the truck-shared delivery and the emission trading scheme}

The ETS is a government-mandated and market-based approach to control pollution by providing economic incentives for reducing pollutant emissions. The government sets a target for the reduction of $\mathrm{CO}_{2}$ emissions and allocates a limit based on the recent statistics about a company's emissions. If a company has emitted less $\mathrm{CO}_{2}$ than the emission limit, it may gain a profit by selling the remaining permits for emitting $\mathrm{CO}_{2}$ and otherwise, it must buy an emitting permit from other companies in an emission trading market. By incorporating the ETS, the model with TSD and ETS can be formulated as follows.

[TSD-E] Minimize $\sum_{v \in V} \sum_{i \in I} \sum_{j \in J} \sum_{t \in T} c_{i j} X_{v i j}^{t}+\sum_{v \in V} \sum_{i \in J} \sum_{j \in I_{v}^{+} \cup K_{i}} \sum_{t \in T} c_{i j} X_{v i j}^{t}+p E$

subject to (1) - (12) and

$$
\sum_{v \in V} \sum_{i \in I} \sum_{j \in J} \sum_{t \in T} e_{v} X_{v i j}^{t}+\sum_{v \in V} \sum_{i \in J} \sum_{j \in I_{v}^{+} \cup K_{i}} \sum_{t \in T} e_{v} X_{v i j}^{t}=l+E
$$

Here, $p$ is the price per ton for emissions trading, $e_{v}$ is the $\mathrm{CO}_{2}$ emissions per $\mathrm{km}$ of a type of truck $v$, and $l$ is the emissions limit. A decision variable $E$ refers both to the excess amount of $\mathrm{CO}_{2}$ emissions exceeding the emissions limit $l$ if $E \geq 0$ and also to the remaining amount of $\mathrm{CO}_{2}$ emissions permits allowed to be sold in the trading market because the emissions are less than the emission limit $l, E<0$. Thus, the company has to purchase extra permits if its total carbon emissions exceed the emission limit. In contrast, it can sell the permits if it has $\mathrm{CO}_{2}$ emissions allowances. Constraint (13) represents that the total $\mathrm{CO}_{2}$ emissions from delivery must be equal to the sum of the emission limit and the excess or remaining amount of $\mathrm{CO}_{2}$ emissions.

\section{Data collection}

To conduct numerical studies using the developed models, data were collected from a Korean mixed feed company and reliable sources. The company is currently operating four factories and two logistics centers located in Daejeon, Incheon, Kyoungnam, Kyoungbuk, Cheonbuk, and Cheonnam. However, we considered only two neighboring factories in Cheonbuk and Cheonnam in this study due to the impracticality in sharing trucks between geographically isolated factories. The distances between factories and customers are summarized in Table 1 and those between customers in Table 2.

Table 1. Distances between factories and customers (unit: $\mathrm{km}$ )

\begin{tabular}{|c|c|c|c|c|c|c|c|c|c|c|c|c|c|c|c|}
\hline & \multicolumn{15}{|c|}{ Customer } \\
\hline & 1 & 2 & 3 & 4 & 5 & 6 & 7 & 8 & 9 & 10 & 11 & 12 & 13 & 14 & 15 \\
\hline Factory 1 & 76 & 63 & 26 & 37 & 45 & 28 & 208 & 36 & 135 & 225 & 176 & 135 & 150 & 210 & 176 \\
\hline Factory 2 & 40 & 85 & 85 & 85 & 85 & 105 & 190 & 140 & 52 & 121 & 66 & 53 & 55 & 168 & 67 \\
\hline
\end{tabular}

Eight customers 1-8 were pre-assigned to factory 1 located in Cheonbuk and seven customers 9-15 to factory 2 located in Cheonnam. Customer demand was obtained from real orders at certain dates as summarized in Table 3.

The factories in Cheonbuk and Cheonnam are operating nine bulk trucks with small carrying capacity of 10 and 15 tons due to cramped driveways to farms. Factory 1 located in Cheonbuk operates five trucks, two 15-ton trucks and three 10-ton trucks, and factory 2 located in Cheonnam operates only four 10-ton trucks. The transport cost was set to 2,943 KRW per km according to real data from the company.

$\mathrm{CO}_{2}$ emissions from the trucks was set to $1.07 \mathrm{kgCO}_{2} / \mathrm{km}$ for 15 -ton trucks and $0.87 \mathrm{kgCO}_{2} / \mathrm{km}$ for 10 -ton trucks, which was calculated using $\mathrm{CO}_{2}$ emissions from $1 \ell$ diesel divided by the fuel efficiency of the truck. $\mathrm{CO}_{2}$ emissions from $1 \ell$ diesel were set to $2.57796 \mathrm{~kg}$ and the fuel efficiency was set to $2.41 \mathrm{~km} / \ell$ for 15 -ton trucks and $2.95 \mathrm{~km} / \ell$ for 10-ton trucks collected from the Korea Energy Economics Institute and Intergovernmental Panel on Climate Change. 
Table 2. Distances between customers (unit: km)

\begin{tabular}{|c|c|c|c|c|c|c|c|c|c|c|c|c|c|c|c|c|}
\hline & \multicolumn{15}{|c|}{ Customer } \\
\hline & & 1 & 2 & 3 & 4 & 5 & 6 & 7 & 8 & 9 & 10 & 11 & 12 & 13 & 14 & 15 \\
\hline \multirow{15}{*}{ 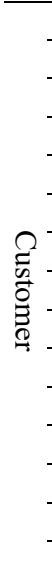 } & 1 & 0 & 48 & 47 & 58 & 44 & 70 & 110 & 102 & 65 & 145 & 77 & 63 & 73 & 130 & 95 \\
\hline & 2 & 48 & 0 & 4 & 9 & 16 & 40 & 75 & 69 & 110 & 190.1 & 114 & 108.1 & 116 & 180 & 133 \\
\hline & 3 & 47 & 4 & 0 & 8.1 & 18 & 34 & 77 & 67 & 108.1 & 188 & 117 & 106.1 & 114 & 180 & 136.1 \\
\hline & 4 & 58 & 9 & 8.1 & 0 & 21 & 26 & 86 & 67 & 117 & 200 & 117 & 115.1 & 114 & 188 & 136.1 \\
\hline & 5 & 44 & 16 & 18 & 21 & 0 & 40 & 71.1 & 85.1 & 108.1 & 175 & 102 & 102 & 102 & 187 & 120.1 \\
\hline & 6 & 70 & 40 & 34 & 26 & 40 & 0 & 74 & 55 & 142 & 207 & 128 & 129.1 & 129.1 & 214 & 154 \\
\hline & 7 & 110 & 75 & 77 & 86 & 71.1 & 74 & 0 & 120.1 & 128 & 161 & 95 & 118 & 100 & 192.1 & 108.1 \\
\hline & 8 & 102 & 69 & 67 & 67 & 85.1 & 55 & 120.1 & 0 & 162.1 & 242 & 174 & 160 & 168 & 233 & 193 \\
\hline & 9 & 65 & 110 & 108.1 & 117 & 108.1 & 142 & 128 & 162.1 & 0 & 110 & 72 & 7 & 40 & 93 & 90 \\
\hline & 10 & 145 & 190.1 & 188 & 200 & 175 & 207 & 161 & 242 & 110 & 0 & 72 & 107 & 76 & 81 & 55 \\
\hline & 11 & 77 & 114 & 117 & 117 & 102 & 128 & 95 & 174 & 72 & 72 & 0 & 70 & 20 & 135 & 18 \\
\hline & 12 & 63 & 108.1 & 106.1 & 115.1 & 102 & 129.1 & 118 & 160 & 7 & 107 & 70 & 0 & 38 & 92.1 & 88 \\
\hline & 13 & 73 & 116 & 114 & 114 & 102 & 129.1 & 100 & 168 & 40 & 76 & 20 & 38 & 0 & 100 & 38 \\
\hline & 14 & 130 & 180 & 180 & 188 & 187 & 214 & 192.1 & 233 & 93 & 81 & 135 & 92.1 & 100 & 0 & 112 \\
\hline & 15 & 95 & 133 & 136.1 & 136.1 & 120.1 & 154 & 108.1 & 193 & 90 & 55 & 18 & 88 & 38 & 112 & 0 \\
\hline
\end{tabular}

Table 3. Customer demand (unit: ton)

\begin{tabular}{|c|c|c|c|c|c|c|c|c|c|c|c|c|c|c|c|}
\hline \multirow[b]{2}{*}{ Customer } & \multicolumn{8}{|c|}{ Factory 1} & \multicolumn{7}{|c|}{ Factory 2} \\
\hline & 1 & 2 & 3 & 4 & 5 & 6 & 7 & 8 & 9 & 10 & 11 & 12 & 13 & 14 & 15 \\
\hline Demand & 14.22 & 7.07 & 8.1 & 5.16 & 8.23 & 3.98 & 10 & 10 & 5.16 & 7.43 & 2.45 & 10 & 4.03 & 5.01 & 4.76 \\
\hline
\end{tabular}

\section{Numerical analysis}

Numerical tests were conducted with an Intel(R) Core(TM) i7 Processor 6500U 2.50GHz PC. All test instances were solved by setting a time limit of 2 hours using an optimization commercial program, CPLEX 12.6.3.0. The trip set $T$ was set to $\{1,2,3,4\}$. Moreover, from the real customer demand set in Table 3 , three additional customer demand sets were generated to investigate the effect of the increase in demand. Fifteen customers were added, each located in the same position as each customer in the existing customer set, was pre-assigned to the factory that does not serve the existing customer and had its demand with the amount of the existing demand multiplied by $\alpha$, which was set to $0.3,0.5$ and 0.7. The existing customer demand set was indexed as 1 and the added demand sets were indexed as 2, 3 and 4 with $\alpha=0.3,0.5$ and 0.7 .

First, with the demand sets, the associated instances with NTSD and TSD were solved. From the test results, this paper analyzed the transport cost and the utilization rate of each truck type. The utilization rate of each truck type (10t or $15 \mathrm{t}$ ) was calculated by (the total demand amount served by the truck type) / (the total capacity amount of the truck type)x100 and denoted by 'Truck type select (\%)'. Then, to identify the effects of truck-sharing and ETS, additional numerical tests were conducted with a variety of emission trading unit costs (or profits), denoted by $p$, which was set to $10000,20000,30000,100000,200000$ and 300000. The emission limit $l$ was set to $954.8 \mathrm{~kg}$, which is equal to $50 \%$ of the emission amount that the case company is emitting in the current delivery practice. For each demand set, the associated problem instance with each emission trading cost was solved. This paper analyzed the results and implications.

Table 4. Test results on NTSD and TSD

\begin{tabular}{|c|c|c|c|c|c|c|c|}
\hline \multirow{3}{*}{$\begin{array}{l}\text { Demand } \\
\text { set }\end{array}$} & \multicolumn{4}{|c|}{ Truck type select (\%) } & \multirow{2}{*}{\multicolumn{2}{|c|}{ Transport cost (KRW) }} & \multirow{3}{*}{ Reduction rate $(\%)^{*}$} \\
\hline & \multirow{2}{*}{$\begin{array}{l}\text { NTSD } \\
15 \mathrm{t}\end{array}$} & \multicolumn{3}{|c|}{ TSD } & & & \\
\hline & & $10 \mathrm{t}$ & $15 \mathrm{t}$ & $10 \mathrm{t}$ & NTSD(a) & TSD(b) & \\
\hline 1 & 29 & 71 & 67 & 33 & $5,874,228$ & $5,273,856$ & 10.22 \\
\hline 2 & 45 & 55 & 65 & 35 & $10,616,000$ & $8,229,216$ & 22.48 \\
\hline 3 & 42 & 58 & 61 & 39 & $12,028,300$ & $8,879,031$ & 26.18 \\
\hline 4 & 38 & 62 & 70 & 30 & $12,881,500$ & $9,026,181$ & 29.93 \\
\hline
\end{tabular}

${ }^{*}$ Reduction rate $=((a)-(b)) /(a) \times 100$

Table 4 shows the test results on NTSD and TSD with an increase in demand. Among eight problem instances solved, 5 were solved to the optimality and the other 3 instances were not. For each of the 3 instances 
in bold font, its best feasible solution found within the solving time limit of 2 hours was reported. The associated gaps with the instances were $2.44 \%, 0.11 \%$ and $1.01 \%$ for NTSD, TSD of demand set 2 and TSD of demand set 3, respectively. Each gap was calculated by (UB-LB)/UBx100, where UB and LB represent the objective function value of the best feasible solution and that of the best lower bound found, respectively. As shown in the table, TSD reduced the transport cost for all demand sets, compared with NTSD. For example, the least reduction of $10.22 \%$ occurred in demand set 1 . In other words, with TSD, the mixed feed company can reduce the transport cost even in the current situation by this rate. TSD is clearly better than NTSD, but the reduction rate may be large. Moreover, with increased demand, the rate increased further. TSD reduced the transport cost by $10.22 \%, 22.48 \%, 26.18 \%$ and $29.93 \%$ for demand sets 1, 2, 3 and 4, respectively. These results suggest that TSD may be very beneficial and offers greater benefits in high-demand situations.

Table 5 shows the test results on NTSD and TSD in ETS with increased demand and emission trading unit cost (or profit) $p$. Forty eight problem instances were solved. As in Table 4, their best feasible solutions found within 2 hours are reported for 14 instances in bold font. The associated gaps were 2.28 2.55\%, 0.70 0.86\% and 0.55 1.21\% for NTSD, TSD of demand set 2 and TSD of demand set 3, respectively. Thirty-four instances in plain font indicate that their optimal solutions were found. The total cost is the sum of the transport cost and the emission cost and a negative sign in the emission cost represents the associated profit. For simplicity, only the total cost and the emission cost are reported. The results were similar to those in Table 4. First, TSD gave significant benefit compared to NTSD in ETS. TSD reduced the total cost by $10.2 \sim 30.06 \%$. The reduction rate increased as demand and $p$ increased. Moreover, although the increase of $p$ might increase the usage of 10-ton trucks, the associated total cost seemed to change insignificantly. For some demand sets, the utilization rates for truck types changed only twice: first, between two TSD problem instances of $p=30000$ and 100000 for demand set 1; secondly, between two TSD problem instances of $p=200000$ and 300000 for demand set 3 . In the cases, the utilization rate of 10-ton trucks increased because 15-ton trucks emit more carbon dioxide than 10-ton trucks. Nevertheless, their total cost reductions were not great at $0.12 \%$ and $0.01 \%$, respectively. They can be easily recalculated using the associated solutions with the prior problem instances. From the results, TSD in ETS may be more beneficial with increased demand and $p$, and ETS may not be effective for encouraging mixed feed companies to reduce their emissions.

Table 5. Test results on NTSD and TSD in ETS

\begin{tabular}{|c|c|c|c|c|c|c|c|c|}
\hline \multirow{3}{*}{$\begin{array}{c}\text { Demand } \\
\text { set }\end{array}$} & \multirow{3}{*}{$\begin{array}{c}p \\
\text { (KRW/ton) }\end{array}$} & \multicolumn{4}{|c|}{ Truck type select $(\%)$} & \multirow{2}{*}{\multicolumn{2}{|c|}{ Total cost / emission cost $(1,000 \mathrm{KRW})$}} & \multirow{3}{*}{ Reduction rate $(\%)$} \\
\hline & & \multicolumn{2}{|c|}{ NTSD } & \multicolumn{2}{|c|}{ TSD } & & & \\
\hline & & $15 \mathrm{t}$ & $10 \mathrm{t}$ & $15 \mathrm{t}$ & $10 \mathrm{t}$ & NTSD & TSD & \\
\hline \multirow{6}{*}{1} & 10,000 & 25 & 75 & 55 & 45 & $5,882 / 8$ & $5,282 / 8$ & 10.20 \\
\hline & 20,000 & 25 & 75 & 55 & 45 & $5,890 / 16$ & $5,291 / 17$ & 10.18 \\
\hline & 30,000 & 25 & 75 & 55 & 45 & $5,899 / 25$ & $5,299 / 25$ & 10.17 \\
\hline & 100,000 & 25 & 75 & 37 & 63 & $5,957 / 83$ & $5,353 / 73$ & 10.15 \\
\hline & 200,000 & 25 & 75 & 37 & 63 & $6,041 / 166$ & $5,426 / 146$ & 10.17 \\
\hline & 300,000 & 25 & 75 & 37 & 63 & $6,124 / 250$ & $5,499 / 220$ & 10.20 \\
\hline \multirow{6}{*}{2} & 10,000 & 38 & 62 & 65 & 35 & $10,640 / 24$ & 8,248 / 19 & 22.48 \\
\hline & 20,000 & 38 & 62 & 65 & 35 & 10,665 / 49 & $8,267 / 38$ & 22.49 \\
\hline & 30,000 & 38 & 62 & 65 & 35 & $10,690 / 74$ & $8,286 / 57$ & 22.49 \\
\hline & 100,000 & 38 & 62 & 65 & 35 & 10,865 / 249 & $8,421 / 192$ & 22.49 \\
\hline & 200,000 & 38 & 62 & 65 & 35 & 11,114 / 498 & $8,613 / 384$ & 22.50 \\
\hline & 300,000 & 38 & 62 & 65 & 35 & $11,364 / 748$ & 8,805 / 576 & 22.51 \\
\hline \multirow{6}{*}{3} & 10,000 & 32 & 68 & 61 & 39 & $12,056 / 28$ & $8,900 / 21$ & 26.18 \\
\hline & 20,000 & 32 & 68 & 61 & 39 & 12,085 / 57 & 8,921 / 42 & 26.18 \\
\hline & 30,000 & 32 & 68 & 61 & 39 & $12,113 / 85$ & 8,942 / 63 & 26.18 \\
\hline & 100,000 & 32 & 68 & 61 & 39 & $12,313 / 285$ & $9,090 / 211$ & 26.18 \\
\hline & 200,000 & 32 & 68 & 61 & 39 & $12,598 / 570$ & $9,301 / 422$ & 26.17 \\
\hline & 300,000 & 32 & 68 & 53 & 47 & $12,884 / 855$ & 9,511 / 612 & 26.17 \\
\hline \multirow{6}{*}{4} & 10,000 & 35 & 65 & 63 & 37 & $12,913 / 31$ & $9,047 / 21$ & 29.93 \\
\hline & 20,000 & 35 & 65 & 63 & 37 & 12,944 / 63 & 9,069 / 43 & 29.94 \\
\hline & 30,000 & 35 & 65 & 63 & 37 & 12,976 / 95 & $9,091 / 64$ & 29.94 \\
\hline & 100,000 & 35 & 65 & 63 & 37 & $13,198 / 317$ & $9,242 / 216$ & 29.97 \\
\hline & 200,000 & 35 & 65 & 63 & 37 & 13,515 / 634 & $9,458 / 432$ & 30.02 \\
\hline & 300,000 & 35 & 65 & 63 & 37 & 13,832 / 951 & 9,675 / 648 & 30.06 \\
\hline
\end{tabular}

${ }^{*}$ Reduction rate $=($ total cost of NTSD - total cost of TSD) / (total cost of NTSD) $\times 100$

\section{Conclusions and future research}


This paper has discussed a case of truck-sharing as an application of SE. The delivery problems of a real mixed feed company taken as a case study were modeled: one for the current NTSD and the other for the proposed TSD. The models were extended with the incorporation of ETS. With the models, a variety of numerical analyses were conducted to identify the effects of truck-sharing and ETS.

From the analysis, the following practical implications were drawn. First, TSD may be very useful for reducing the transport cost, especially in high-demand situations. The case company can reduce its transport cost by over $10 \%$ with TSD, even in the current situation. Second, TSD in ETS may be more beneficial with increased demand and emission trading unit cost (or profit). Third, although a huge emission trading unit cost (or profit) increases the usage of trucks with small emissions, ETS may not be effective for encouraging mixed feed companies to reduce their emissions due to the small proportion of the emission cost to the total cost.

This study can be extended in several ways. First, truck-sharing occurred among factories belonging to a company in this paper. From a wider perspective, the parties willing to share their trucks can be other companies in similar industries or specialized firms offering truck-sharing service. Future research considering such parties would be interesting. Second, this research can be extended by considering a problem with time window restrictions on customers or factories. Such restrictions can be found in the applications such as food industry and passenger transportation. Third, a carbon tax as a carbon control policy can be considered in further study.

\section{Acknowledgement}

This work was supported by INHA UNIVERSITY Research Grant.

\section{References}

Böckmann, M., 2013. The shared economy: it is time to start caring about sharing; value creating factors in the shared economy. <http://thelovettcenter.com/wp-content/uploads/2014/11/bockmann-shared-economy.pdf>.

Cannon, S., Summers, L.H., 2014. How Uber and the sharing economy can win over regulators. Harvard Business Review. <http://wpressutexas.net/cs378h/images/4/48/How_Uber_and_the_Sharing_Economy_Can_Win_Over_Regulators.pdf > .

Cattaruzza, D., Absi, N., Feillet, D., Vigo, D., 2014. An iterated local search for the multi-commodity multi-trip vehicle routing problem with time windows. Computers \& Operation Research 51, 257-267.

Cheng, M., 2016. Sharing economy: A review and agenda for future research. International Journal of Hospitality Management 57, 60-70.

Demaio, P., 2009. Bike-sharing: history, impacts, models of provision, and future. Journal of Public Transportation 12, 41-56.

Dredge, D., Gyimóthy, S., 2015. The collaborative economy and tourism: critical perspectives, questionable claims and silenced voices. Tourism Recreation Research 40, 286-302.

Forno, F., Garibaldi, R., 2015. Sharing economy in travel and tourism: the case of home-swapping in Italy. Journal of Quality Assurance in Hospitality \& Tourism 16, 202-220.

Hernandez, F., Feillet, D., Giroudeau, R., Naud, O., 2016. Branch-and-price algorithms for the solution of the multi-trip vehicle routing problem with time windows. European Journal of Operational Research 249, 551-559.

Huwer, U., 2004. Public transport and car-sharing-benefits and effects of combined services. Transport Policy 11, 77-87.

Islam, S., Olsen, T., Ahmed, M.D., 2013. Reengineering the seaport container truck hauling process: Reducing empty slot trips for transport capacity improvement. Business Process Management Journal 19, 752-782.

Islam, S., Olsen, T., 2014. Truck-sharing challenges for hinterland trucking companies: a case of the empty container truck trips problem. Business Process Management Journal 20, 290-334.

Katzev, R., 2003. Car sharing: a new approach to urban transportation problems. Analyses of Social Issues and Public Policy 3 , 65-86.

Koopman, C., Mitchell, M., Thierer, A., 2015. The sharing economy and consumer protection regulation: the case for policy change. The Journal of Business, Entrepreneurship \& the Law 8, 528-545.

Lee, T.-H., Min, J.-U., Park, J.-S., 2010. Analyzing impact of financial information sharing on supply chain performance and stability: system dynamics approach. Journal of International Logistics and Trade 8, 91-116.

Lin, J.R., Yang, T.H., 2011. Strategic design of public bicycle sharing systems with service level constraints. Transportation Research Part E 47, 284-294.

Lin, J.R., Yang, T.H., Chang, Y.C., 2013. A hub location inventory model for bicycle sharing system design: formulation and solution. Computers \& Industrial Engineering 65, 77-86.

Martin, C.J., 2016. The sharing economy: a pathway to sustainability or a nightmarish form of neoliberal capitalism?. Ecological Economics 121, 149-159.

Montoya-Torres, J.R., Franco, J.L., Isaza, S.N., Jiménez, H. F., Herazo-Padilla, N., 2015. A literature review on the vehicle routing problem with multi depots. Computers \& Industrial Engineering 79, 115-129.

Nair, R., Miller-Hooks, E., Hampshire, R.C., Bušić, A., 2013. Large-scale vehicle sharing systems: analysis of Vélib. International Journal of Sustainable Transportation 7, 85-106.

PwC, 2015. The sharing economy-sizing the revenue opportunity. <http://www.pwc.co.uk/issues/megatrends/collisions/sharingecono 
my/the-sharing-economy-sizing-the-revenue-opportunity.html>.

Queensland Tourism Industry Council, 2014. The sharing economy.<https://www.qtic.com.au/sites/default/files/140714_draft_shari ng_economy_paper.pdf>.

Schor, J., 2014. Debating the sharing economy. Great transition initiative. <http://www.tellus.org/pub/Schor_Debating_the_Sharing_ Economy.pdf>.

Wosskow, D., 2014. Unlocking the sharing economy: an independent review. <http://collaborativeeconomy.com/wp/wp-content/upl oads/2015/04/Wosskow-D.2014.Unlocking-the-UK-Sharing-Economy.pdf >.

Zervas, G., Proserpio, D., Byers, J., 2016. The rise of sharing economy: estimating the impact of Airbnb on the hotel industry. Boston Univ. School of Management Research Paper, <http://cs-people.bu.edu/dproserp/papers/ airbnb.pdf>. 